\title{
DiOITOS
}

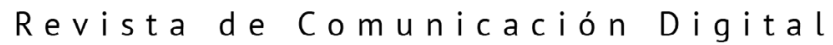

\section{La comunicación política de la derecha radical en redes sociales. De Instagram a TikTok y Gab, la estrategia digital de Vox}

\section{The political communication of the right-wing radicals on social networks. From Instagram to TikTok and Gab, Vox's digital strategy.}

Andrea Castro Martínez

andreacastro@uma.es

Universidad de Málaga
(iD) Pablo Díaz Morilla

Pablodmorilla@uma.es

EADE University of Wales Trinity Saint David Universidad de Málaga

\section{Resumen}

El espacio digital y las redes sociales han adquirido gran importancia en la comunicación política. Se han convertido en canales en los que los partidos difunden sus argumentarios y fidelizan a sus simpatizantes y donde los líderes demuestran su carisma. Este trabajo analiza la estrategia digital que emplea Vox en España a través de su página web y sus cuentas en plataformas sociales. Mediante un análisis cualitativo y cuantitativo se estudian la página web y los perfiles de la formación en Facebook, Twitter, Telegram, Flickr, Youtube, Instagram, TikTok y Gab. El uso de estos canales difiere en su formato y estilo, ya que se dirigen a distintos perfiles de públicos, pero todo el contenido generado por la formación para ser empleado en la esfera digital responde a los mismos patrones discursivos. Se caracteriza por la simplificación y el empleo de un lenguaje directo y claro, con expresiones beligerantes y de llamada a la acción, que explota para descalificar y ridiculizar a sus adversarios políticos y ensalzar a sus líderes. Destaca su uso de redes enfocadas al usuario joven, como Youtube, Instagram o TikTok, en las que adapta sus recursos estilísticos. También resulta relevante su presencia en Gab, una red social caracterizada por no limitar ningún contenido y cuyos usuarios se asocian a posicionamientos políticos de extrema derecha. A través de las redes sociales Vox ofrece a sus simpatizantes contenido que no obtiene cobertura en medios convencionales generalistas y con el que refuerza su estrategia política en el espacio físico.

Edita: Miguel Vicente-Mariño

Recibido: $16 / 12 / 2020$

Aceptado: 01/05/2021

Cómo citar este artículo:

Castro Martínez, A. y Días Morilla, P. (2021). La comunicación política de la derecha radical en redes sociales. De Instagram a TikTok y Gab, la estrategia digital de Vox. Dígitos. Revista de Comunicación Digital, 7: 67-89. DOI: $10.7203 /$ rd.v1i7.210 


\begin{abstract}
The digital space and social networks have become very important in political communication. They are channels where parties disseminate their arguments and build loyalty with their supporters, and where leaders demonstrate their charisma. This paper analyses Vox's digital strategy in Spain through its website and its accounts on social platforms. Using a qualitative and quantitative analysis, we study the website and the organisation's profiles on Facebook, Twitter, Telegram, Flickr, Youtube, Instagram, TikTok and Gab. The use of these channels differs in format and style, as they are aimed at different audience profiles, but all the content generated by the formation for use in the digital sphere responds to the same discursive patterns. It is characterised by simplification and by direct and clear language, with belligerent expressions and calls to action, which Vox utilises to disqualify and ridicule its political opponents and glorify its leaders. Its use of networks focused on young users, such as Youtube, Instagram and TikTok, where it adapts his stylistic resources, stands out. It is also interesting its presence on Gab, a social network characterised by the absence of content limitations and whose users are associated with extreme right-wing political opinions. Vox offers their supporters an attractive self-representation through its social networks by providing polemical and direct content with a very simplified approach.
\end{abstract}

\title{
Keywords
}

Political communication, social networks, TikTok, Instagram, Gab, Vox digital de Vox

\section{Introducción}

Vivimos un periodo de erosión democrática que se ha visto potenciada por la crisis global derivada de la pandemia de la COVID-19. En los últimos años ya se había constatado la tendencia del surgimiento y consolidación de alternativas políticas enfrentadas a los partidos históricos y el auge de la extrema derecha y los populismos tanto en los Estados Unidos y Europa como en otras regiones (Main, 2018; Daniels, 2018; Forscher y Kteily, 2020). Desde hace tiempo la fragmentación tanto de la esfera mediática mundial como de las audiencias permite con mayor facilidad amplificar discursos contrapuestos y alimentar la confrontación ideológica. Sin embargo, en 2020 la polarización social ha aumentado exponencialmente.

Esto se debe en parte a la democratización de la capacidad de generación de contenidos que hace que vivamos en una época de desinformación, infoxicación y fake news (Lotero-Echeverri, Romero-Rodríguez y Pérez-Rodríguez, 2018; Magallón, 2020). Incluso la Organización Mundial de la Salud ha acuñado el término Infodemia (Allahverdipour, 2020; Alfonso y Fernández, 2020). Las redes sociales y las plataformas digitales juegan un papel fundamental en la difusión de contenidos y en la homofilia entre los componentes de una comunidad (Lozares y Verd, 2012; Valera-Ordaz, Calvo y LópezGarcía, 2018). Y es que a través de ellas las entidades y personas pueden establecer una comunicación "fluida y eficaz con grupos específicos de interés, incluyendo esto desde la posibilidad de atender la necesidad de pertenencia social hasta facilitar la proyección y posicionamiento de empresas, bienes, servicios, o incluso para ser utilizadas en campañas políticas" (Hütt, 2012: 121). 
En este contexto, la presente investigación centra su objeto de estudio en la comunicación online de uno de los nuevos actores del panorama político español: el partido de derecha radical Vox. El objetivo general consiste en analizar la estrategia digital de Vox en las redes sociales y plataformas a través de las cuales construye su marca en la red. Como objetivos secundarios se han planteado los siguientes:

- Determinar y estudiar los elementos que componen la identidad digital de Vox.

- Identificar los recursos que utiliza Vox en redes sociales para conformar su planteamiento comunicativo y difundir su discurso.

- Establecer las características del contenido digital producido por Vox para movilizar a su público en los diferentes canales online donde tiene presencia.

\section{Marco teórico}

En la 'Galaxia Internet' (Castells, 2001) las plataformas y redes sociales han modificado las formas y modos de comunicación en la actualidad tanto en el ámbito privado como en el público y han dotado a intercambios sociales informales de mayor repercusión y permanencia (Van Dijck, 2019). Una de las consecuencias de su irrupción ha sido la modificación del paradigma comunicativo (Aruguete, 2017) potenciando la bidireccionalidad y la simetría (Alonso, 2015).

Y es que el desarrollo de Internet ha llevado aparejado el surgimiento de múltiples plataformas sociales y herramientas digitales que han modificado el contexto comunicativo y los pilares clásicos del sistema mediático. La estructura vertical y unidireccional de la comunicación protagonizada por los medios se ha visto afectada por el desarrollo de nuevos espacios como las redes sociales, que la han transformado hacia la horizontalidad, bidireccionalidad e interactividad (Herrero-Curiel, 2011:1116).

Además, el nuevo contexto tecnológico también ha afectado a los negocios periodísticos (Capoano, 2018) debido a que la red y la multiplicidad de contenido e información que alberga elimina las restricciones de acceso a la información del sistema tradicional (Cebrián, 2008). Esto se debe a que los medios convencionales ya no son los únicos que seleccionan la información que consideran noticiable en su función de gatekeepers (White, 1950; Wolf, 2005).

Esto se debe a que las redes sociales han logrado a nivel mundial una penetración de casi el 50\% (Hootsuite, 2020). En España el 90\% de la población mayor de 16 años utiliza Internet y el $77,5 \%$ lo hace a diario (INE, 2019) y se conecta fundamentalmente desde dispositivos móviles como los teléfonos inteligentes (ONTSI, 2019). Según los datos de IAB Spain (2020), las redes sociales más utilizadas en España, por este orden, son Whatsapp, Instagram, Facebook, Byte, Youtube, Telegram, Spotify, Twitter, TikTok, Twitch y HouseParty, entre otras.

En este ecosistema móvil (Aguado, Feijóo y Martínez, 2014) la participación y la personalización (Ruano, 2009) son fundamentales para la conversación en línea, donde se han desarrollado nuevos esquemas y narrativas (Freitas y Castro, 2010). Entre los distintos usos que se dan a las redes sociales destacan los fines políticos (Rodríguez, 2018), ya que "Ios medios sociales se articulan como espacios donde se redefine el ejercicio del poder" (de Aguilera y Casero, 2018:5). Así, la relevancia que han adquirido las plataformas sociales en la política se debe a que permiten reflejar opiniones, preferencias y posicionamientos de los agentes políticos y de sus comunidades, de forma que contribuyen a encuadrar su agenda política y comunicativa (Nulty et al., 2016). 
Es lo que algunos autores denominan ciberpolítica (Cotarelo, 2013) y se basa en que las redes sociales tienen capacidad para influir sobre la fijación de la agenda pública (Amado y Tarullo, 2015; Sierra y Lavín, 2019) por lo que los partidos políticos las emplean "en los procesos de construcción de la agenda pública -agenda setting o agenda building-" (Martín et al., 2020:272). El uso de plataformas de medios sociales y servicios de mensajería instantánea como medios de comunicación con los públicos influye en los procesos políticos y electorales (Rodrigues, 2020) ya que la participación en línea está relacionada de forma positiva con la participación en el entorno offline (VesnicAlujevic, 2012). De hecho, los mensajes políticos que los usuarios reciben a través de redes sociales, principalmente si proceden de contactos con los que mantienen amistad, pueden aumentar la intención de voto (Min, 2015). Es por ello que los mensajes publicados en estas plataformas pueden ser estudiados para detectar tendencias de opinión, como ocurre en el caso de Twitter donde ya se aplican métodos de análisis de sentimiento (Baviera, 2017).

Los actores populistas emplean los medios sociales para articular su ideología y visibilizar y expandir sus mensajes (Engesser et al., 2017). Esto se debe a que el populismo se presenta ligado a otros conjuntos de ideas y posicionamientos políticos, de modo que logra politizar quejas que se convierten en relevantes en su contexto propio (Mudde y Rovira, 2018).

Por su parte, los usuarios consumen contenido político de entretenimiento en redes sociales, como es el caso de TikTok, que se caracteriza por albergar contenidos de consumo rápido y desenfadado (Ballesteros, 2020), y ha tenido en el último año un desarrollo sin precedentes, convirtiéndose en "una fuerza formidable en la política americana" (Guinaudeau, Vottax y Munger, 2020:1).

Sin embargo, pese al consumo de contenidos la participación real de los usuarios en cuanto a contenidos políticos de entretenimiento, según Berrocal-Gonzalo, CamposDomínguez y Redondo-García (2014:70), es limitada:

El prosumo de «politainment» en Internet se caracteriza por ser consumido masivamente por los usuarios pero por una acción muy pasiva en su producción. El prosumidor basa su consumo y producción en acciones colaborativas, pero no es el productor hegemónico de estos contenidos. Si bien es cierto que cada vídeo recibe un número significativo de comentarios, no es un volumen proporcional al número de reproducciones: como se ha comprobado, solo un porcentaje reducido de reproducciones se traduce también en comentarios.

Las plataformas digitales posibilitan el acercamiento al electorado joven (Hendricks y Denton, 2010) y transmitir el ideario a través de la personalización como estrategia política, encarnada en los líderes de cada partido (Orejuela, 2009). La política no escapa al culto a la imagen y el individualismo propio de las redes sociales, que potencian el "fortalecimiento del liderazgo individual frente a las estructuras partidistas tradicionales" (López-García, 2016:151). Las plataformas sociales permiten a los políticos, sean jefes de gobierno o miembros de cualquier partido, trabajar su liderazgo en una campaña política digital permanente que se fundamenta en la creación y difusión de recursos audiovisuales impactantes (Lalancette y Raynauld, 2019). La narración digital a través de imágenes es relevante en la comunicación política ya que permite construir estrategias para resaltar a los candidatos a través de su trayectoria, su equipo y su legitimidad para un cargo (Liebhart y Bernhardt, 2017). En cuanto al contenido de las publicaciones políticas en redes sociales, las imágenes resultan más atractivas que la información textual y, en concreto, los rostros o primeros planos de los candidatos llaman más la 
atención que las fotografías grupales, planos generales o imágenes gráficas (PuentesRivera, Rúas-Araújo y Dapena-González, 2017).

Según un estudio de Ekman y Widholm (2017) sobre Instagram, pese al potencial democrático e interactivo de la comunicación política visual digital la mayoría de los políticos evitan las interacciones con el público, aunque estén preocupados por su marca personal. Y es que los líderes políticos en Instagram "se centran en proporcionar un constante flujo de noticias políticas, opinión, intereses personales, y otra información" (Parmelee y Roman, 2019:7). Según (Pallarés y Ortega, 2017:121)

“Independientemente de la red social, la presencia de los políticos en estas plataformas digitales parece centrarse más en los números, en conseguir el mayor número de seguidores y trending topics, que en la verdadera interacción con los usuarios. Pero los seguidores, fans o followers no son votos, por lo que es más importante tener una audiencia activa, que haga retweet o de al botón de ‘me gusta', que tener millones de usuarios (Cha, Haddadi, Benevenuto y Gummadi, 2010; Marwick y Boyd, 2010)."

Otro aspecto relevante es que en redes sociales los intercambios comunicativos sobre cuestiones vinculadas a la política tienen lugar principalmente entre individuos con preferencias ideológicas similares, lo que debido a procesos como una exposición selectiva a las fuentes y la información a la que se es afín o la segregación ideológica puede producir lo que se conoce como el efecto de cámara de eco (Colleoni, Rozza y Arvidsson, 2014; Barberá et al., 2015).

En esta línea en 2016 surgió Gab, que es una red social lanzada tras la moderación de contenidos en otros canales como Facebook o Twitter. En ella han recalado muchos usuarios cuyas cuentas han sido limitadas en otras redes por emitir discursos de odio y vinculados a posiciones extremistas, por lo que se trata de una plataforma muy orientada políticamente que constituye una cámara de eco de orientación derechista y cuyos usuarios raramente son impactados por contenidos de líneas ideológicas diferentes (Lima et al., 2018). Se basa en mensajes multimedia de hasta 300 caracteres y una estética similar a la de Twitter y en ella es común encontrar como símbolo al personaje Pepe the Frog, un meme de Internet de una rana antropomórfica de la que se han apropiado usuarios de tendencia derechista. Esta red atrae a usuarios de extrema derecha, teóricos de la conspiración y trolls y la presencia en ella de discursos de odio es mucho mayor que en Twitter (Zannettou et al., 2018) ya que pese a que se autoproclama la red social de la libre expresión está dominada por individuos asociados al movimiento político alt-right de los Estados Unidos (Zhou et al., 2019). En un reciente estudio Kalmar, Stevens y Worby (2018) demuestran que esta red acoge ahora un contenido más abiertamente antisemita que Twitter y lo ilustran a través de las informaciones que se recogen en Gab sobre el financiero judío-estadounidense George Soros, a los que los partidarios de la derecha populista acusan, entre otras muchas cuestiones, de instigar la migración masiva de refugiados musulmanes a Europa.

\subsection{Vox en el panorama político español}

La esfera de la comunicación política española se ha visto profundamente afectada por la irrupción de Podemos, Ciudadanos y Vox como nuevos partidos y el uso estratégico que han hecho de la comunicación digital (Reyero y Cordero, 2020). En la actualidad el panorama político español se caracteriza por su fragmentación y confrontación, 
además de por la desafección de parte de la población, entre la que destacan los jóvenes (Morán y Benedicto, 2016; Fontaneda y Sánchez-Vítores, 2018).

En este contexto Vox se ha establecido como un partido posicionado a la derecha del Partido Popular y ha alcanzado representación en el Congreso de los Diputados. Ha aumentado su base social en los últimos años y está desplegando diferentes estrategias comunicativas para alcanzar a nuevos simpatizantes. Aladro y Requeijo (2020) desarrollaron un estudio sobre las 81 publicaciones realizadas por Vox en Instagram con un mayor nivel de interacción durante los dos meses previos a las elecciones generales de 2019. Concluyeron que esta red era usada de forma exitosa por Vox para simplificar su discurso a través de la selección temática, el uso de un lenguaje propio y la hiperpresencia de sus líderes, en concreto de Santiago Abascal (Aladro y Requeijo, 2020). En Twitter sin embargo la agrupación política ha visto cómo su cuenta ha llegado a ser bloqueada por atentar contra el cumplimiento de las normas de esta red social en lo que se refiere a la incitación al odio tras una publicación sobre la política socialista Adriana Lastra (Corellano, 2020).

\section{Metodología}

Este estudio se enmarca en las investigaciones sobre comunicación política y redes sociales y emplea un diseño metodológico basado en datos cuantitativos y cualitativos sobre la presencia digital de Vox. La muestra está compuesta por los distintos soportes que emplea la formación en el ámbito digital como son su página web y sus perfiles oficiales en Facebook, Twitter, Telegram, Flickr, Youtube, Instagram, TikTok y Gab. Además, las tres últimas redes mencionadas han sido objeto de una segunda fase de análisis al ser las que se dirigen a un público mayoritariamente joven. En el caso de Gab se ha considerado así no solo por el perfil de sus usuarios a nivel genérico sino porque se trata de una plataforma que aún tiene poca penetración en España y a la que la audiencia de menor edad puede acceder con más facilidad debido a su familiaridad con el uso de un mayor número de perfiles sociales.

Como métodos y técnicas de investigación para la obtención de datos se ha realizado un análisis de contenido, cuantitativo y cualitativo, de la página web y de los perfiles en redes sociales digitales de Vox. Se ha aplicado a los diferentes soportes digitales de los que dispone la formación, como son su página web y las redes sociales donde está presente, en concreto Facebook, Twitter, Instagram, Flickr, Youtube, Gab y TikTok. También se ha incluido la herramienta de mensajería instantánea Telegram, ya que Vox la incluye en el apartado de su red en el que referencia el resto de sus perfiles. De este modo se ha diseñado una tabla de análisis (tabla 1) que operacionaliza distintas variables, unidades de análisis, categorías y subcategorías para identificar los elementos y recursos que utiliza el partido en redes sociales en su discurso hacia los jóvenes. El proceso de recolección de datos y codificación ha sido desarrollado por un único investigador y se ha desarrollado de forma descriptiva para reducir el riesgo de interpretación subjetiva durante esta etapa del análisis. En una segunda fase ambos investigadores han trabajado de forma conjunta en la interpretación de la información obtenida.

A lo largo del proceso de análisis de las publicaciones se han identificado distintos contenidos en cada red por su valor ilustrativo y se han incorporado a la exposición de los resultados del trabajo (tabla 5). 
Tabla 1. Análisis de contenido de las publicaciones en redes sociales. Elaboración propia.

\begin{tabular}{|c|c|c|}
\hline Red social & Fecha & Hora \\
\hline \multirow{2}{*}{ Autoría } & \multicolumn{2}{|l|}{ Propia } \\
\hline & Contenido ajeno & Identificación del autor/a \\
\hline \multirow{7}{*}{$\begin{array}{l}\text { Tipo de } \\
\text { publicación }\end{array}$} & \multicolumn{2}{|l|}{ Imagen fija } \\
\hline & \multicolumn{2}{|l|}{ Vídeo } \\
\hline & \multicolumn{2}{|l|}{ Stories } \\
\hline & \multicolumn{2}{|l|}{ Reels } \\
\hline & \multicolumn{2}{|l|}{ Fleets } \\
\hline & \multicolumn{2}{|l|}{ Momentos } \\
\hline & \multicolumn{2}{|l|}{ Otro } \\
\hline \multirow{7}{*}{$\begin{array}{l}\text { Recursos } \\
\text { técnicos }\end{array}$} & $\begin{array}{l}\text { Imagen: Fotografía / } \\
\text { Ilustración/ Vídeo }\end{array}$ & $\begin{array}{l}\text { Plano/ Angulación/ Perspectiva/ Uso del color/ } \\
\text { lluminación/ Secuencialidad/ Edición }\end{array}$ \\
\hline & \multirow{2}{*}{ Sonido } & Música \\
\hline & & Audio \\
\hline & \multirow{4}{*}{ Texto } & Mensajes escritos \\
\hline & & Emoticonos \\
\hline & & Etiquetas \\
\hline & & Rótulos \\
\hline \multirow{15}{*}{$\begin{array}{l}\text { Recursos } \\
\text { discursivos }\end{array}$} & \multicolumn{2}{|l|}{ Acción } \\
\hline & \multicolumn{2}{|l|}{ Escenario } \\
\hline & \multirow{5}{*}{ Personajes } & Sexo \\
\hline & & Identificables/ anónimos \\
\hline & & Edad \\
\hline & & Raza/Etnia \\
\hline & & Apariencia física \\
\hline & \multirow{5}{*}{ Lenguaje verbal } & Temática \\
\hline & & Expresiones \\
\hline & & Diálogos \\
\hline & & Terminología \\
\hline & & Llamada a la acción \\
\hline & \multirow{3}{*}{ Lenguaje no verbal } & Gestos \\
\hline & & Manejo del espacio \\
\hline & & Acciones \\
\hline
\end{tabular}

Tabla 2. Año de creación de los perfiles de redes sociales de Vox. Elaboración propia.

\begin{tabular}{|l|l|}
\hline Año & Red \\
\hline 2013 & Twitter \\
\hline 2014 & Facebook y Youtube \\
\hline 2016 & Instagram \\
\hline 2017 & Flickr \\
\hline 2018 & Telegram \\
\hline 2020 & TikTok y Gab \\
\hline
\end{tabular}

El análisis de métricas en las redes y plataformas sociales en las que tiene presencia el partido: se ha monitorizado su actividad, para determinar y estudiar los elementos que componen la identidad digital de Vox. Para ello se ha utilizado software específico como Hashtagify y Fan Page Karma.

La recogida de los datos se ha llevado a cabo entre el 15 de noviembre y los primeros 
días del mes de diciembre de 2020. No obstante, el periodo de análisis es mucho más amplio, ya que abarca desde la fecha de creación de los perfiles oficiales de Vox (tabla 2) en las diferentes redes sociales hasta el día 6 de diciembre de 2020.

\section{Resultados}

\section{Página web}

Los resultados del análisis de los soportes digitales de comunicación que utiliza Vox revelan que su página web aglutina toda la información de la formación. Se trata de una web de navegación sencilla y muy visual que dispone en la parte central superior de la marca del partido, de todos sus perfiles sociales y una llamada a la acción para lograr afiliados A continuación aparece un menú estático y dispone de otro desplegable en la parte inferior que da acceso a aspectos destacados como el manifiesto fundacional, su normativa, órganos internos, medidas y propuestas, recursos para hacerse afiliado o realizar donaciones, o la sala de prensa virtual, entre otras. Su estética es similar a la de cualquier medio digital, con una gran noticia de portada a tres columnas y otras destacadas a menor tamaño, además de incluir en el lateral un formato gráfico similar a un rascacielos publicitario que enlaza a su última campaña contra los Presupuestos Generales. También dispone de robapáginas y botones gráficos que enlazan a diferentes contenidos. Los mensajes textuales son claros y concisos, empleados a modo de titular de prensa y de proclamas ideológicas. La página principal también incluye una videoteca con las piezas visuales más destacadas. Respecto a la paleta de colores empleada en la página web predomina el verde, como color corporativo, y en la parte superior aparece la bandera de España y un crespón negro (imagen 1).

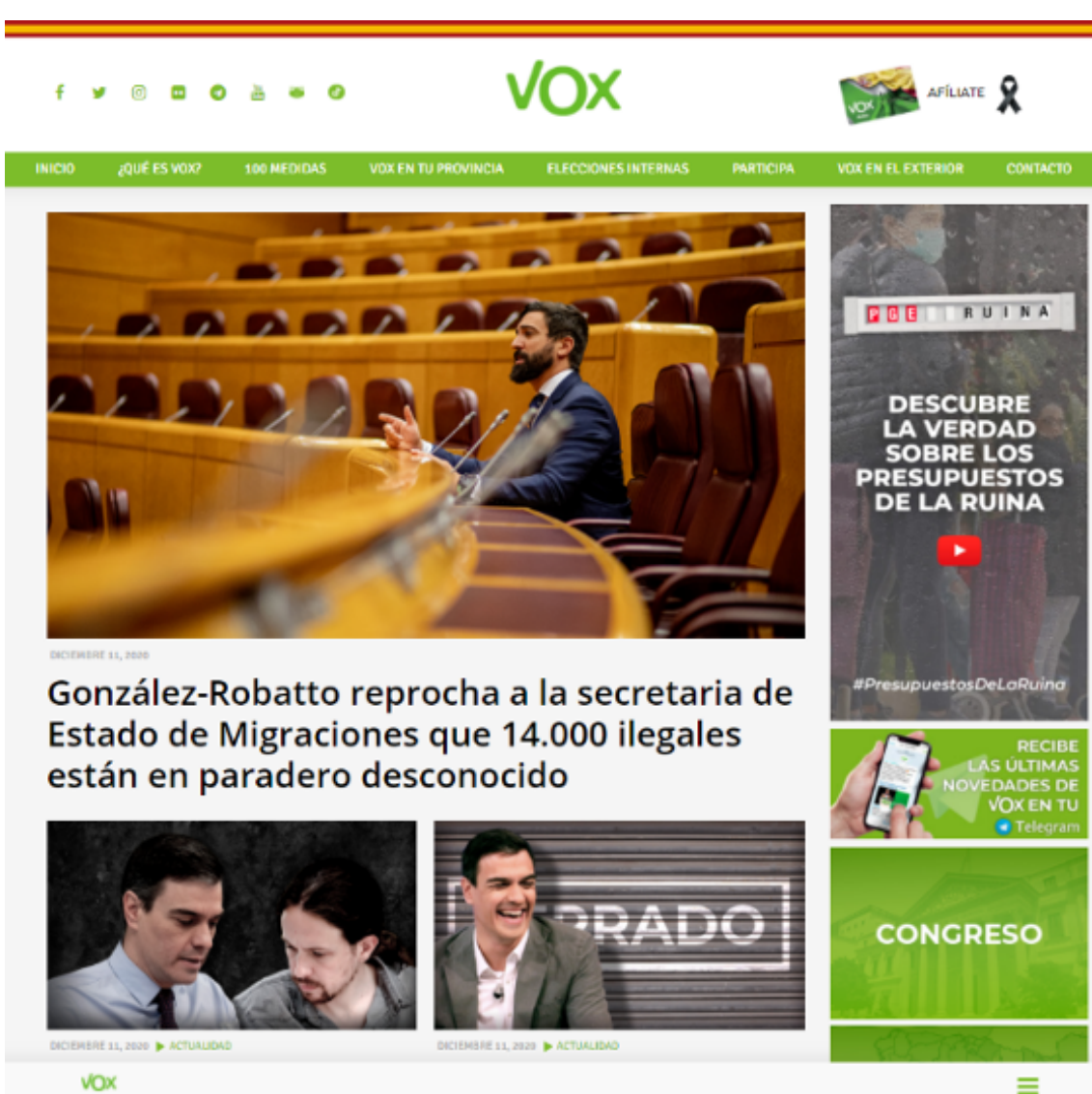

Imagen 1. Página web de Vox. Fuente: Vox
Vox dispone de perfiles sociales en Facebook, Twitter, Youtube, Flickr, Instagram, TikTok y Gab, además de en la plataforma de mensajería instantánea Telegram. En todas ellas acumula una importante comunidad de seguidores y anima en su descripción biográfica a unirse al partido y a sus perfiles, normalmente acompañados de iconos de la bandera española y del brazo como símbolo de fuerza (tabla 3). Todas las cuentas permanecen actualizadas, aunque la cadencia de publicaciones no es homogénea, ya que plataformas como Twitter o Flicker contienen un mayor número de publicaciones. 
Tabla 3. Perfiles de redes sociales de Vox. Fuente: Elaboración propia.

\begin{tabular}{|c|c|c|c|c|c|}
\hline Red social & Perfil & $\begin{array}{l}\text { Comunidad/ } \\
\text { Seguidores }\end{array}$ & $\begin{array}{l}\text { No Publi- } \\
\text { caciones }\end{array}$ & $\begin{array}{l}\text { Segui- } \\
\text { dos }\end{array}$ & Bio \\
\hline Facebook & @VOXEspaña & 602117 & - & - & $\begin{array}{l}\text { VoX somos el único partido } \\
\text { político en España que } \\
\text { propone la eliminación de } \\
\text { miles de cargos políticos, } \\
\text { eliminando las comunidades } \\
\text { autónomas, el Senado, y miles } \\
\text { de ayuntamientos, para así } \\
\text { poder bajar drásticamente los } \\
\text { impuestos. } \\
\text { Ya nos han recortado bastante } \\
\text { a nosotros. Ha llegado el } \\
\text { momento de recortarles a } \\
\text { ellos, a los políticos. }\end{array}$ \\
\hline Twitter & @vox_es & $429,3 \mathrm{mil}$ & $52,2 \mathrm{mil}$ & 1225 & $\begin{array}{l}\text { Únete a nuestro canal de } \\
\text { Telegram: } \\
\text { http://t.me/voXtelegram } \\
\text { No te pierdas nuestros vídeos } \\
\text { YouTube: http://youtube.com/ } \\
\text { user/voxespana }\end{array}$ \\
\hline Youtube & VOX España & $\begin{array}{l}378 \text { mil } \\
\text { seguidores/ } \\
117.838 .275 \\
\text { visualizaciones }\end{array}$ & 119 & - & - \\
\hline Flicker & VOX España & $\begin{array}{l}147 \\
\text { seguidores/ } \\
2,6 \text { millones de } \\
\text { vistas }\end{array}$ & $\begin{array}{l}183 \\
\text { álbumes }\end{array}$ & 0 & - \\
\hline Telegram & & 53202 & & - & $\begin{array}{l}\text { Canal oficial de alertas de VOX } \\
\text { España. Recibirás las últimas } \\
\text { noticias y vídeos para estar } \\
\text { informado y poder compartir } \\
\text { en redes sociales y con } \\
\text { amigos. \#EspañaViva }\end{array}$ \\
\hline Instagram & vox_es & $616 \mathrm{mil}$ & 1900 & 193 & Somos la España Viva Ẽ \\
\hline TikTok & vox_espana & $32,8 \mathrm{k}$ & 9 & 0 & $\begin{array}{l}\text { Cuenta oficial de VOX } \\
\text { \#PorEspaña }\end{array}$ \\
\hline Gab & $\begin{array}{l}\text { @VOX_- } \\
\text { Espana_ }\end{array}$ & $2,8 \mathrm{k}$ & 332 & 43 & $\begin{array}{l}\text { Sin miedo a nada ni a nadie } \\
\text { \#PorEspaña }\end{array}$ \\
\hline
\end{tabular}

\section{Facebook}

Vox tiene una página de Facebook verificada como partido político. Aglutina 449.274 me gusta como página, 602.187 seguidores y 845 registros de visita. También usa los eventos para dar información de sus distintos actos y convocatorias Ha publicado 4955 fotos en 49 álbumes y 49 vídeos largos organizados en 3 listas de reproducción. Desde el año 2019 ha colgado casi 1000 piezas de vídeo en el muro de su página. 
El vídeo más popular de la fanpage es una reclamación al ministro Marlaska para que comparezca por el traslado de inmigrantes de Canarias a Granada y ha alcanzado los 628 comentarios, 9100 Me gusta y se ha compartido 3000 veces.

Sus publicaciones van acompañadas de textos a modo de titular, donde son habituales las etiquetas y los emoticonos, además del uso de signos exclamativos. Emplea un lenguaje directo, incluso agresivo, con abundancia de terminología bélica

\section{Twitter}

En Twitter dispone de un perfil verificado con una cabecera gráfica en la que aparece una crítica a los Presupuestos Generales del Estado, a los que se refiere como "PGR Ruina”. El tuit inicial fijado es: "“ÚNETE A VOX! Forma parte de la alternativa que no tiene miedo a nada ni a nadie. $\mathbb{Z}^{\prime \prime}$. La cuenta tiene los mensajes directos habilitados.

En cuanto a las publicaciones no todo el contenido es propio, sino que sigue una estrategia de retuitear muchas publicaciones de otras agrupaciones autonómicas y regionales del partido y de los perfiles de sus dirigentes, así como de simpatizantes. No contesta de forma habitual a los tuits, su relación con las menciones que recibe suele ser el retuiteo También usan publicaciones sin contenido multimedia, ya sean fotos o tuits, además de links a contenido propio en otros soportes o a noticias o periodistas de medios afines, como Alvise Pérez o La Mañana de Federico Jiménez Losantos.

El lenguaje empleado es similar al de Facebook e incluye multitud de apelaciones directas a los usuarios, a los que interpela a través de recursos como las preguntas o los call to action.

\section{Flickr}

En Flickr la formación dispone de una Cuenta Pro de suscripción y sus fotos acumulan más de 2,6 millones de vistas. Sin embargo, sus fotos más populares no tienen métricas muy destacadas: las 25 fotos con más favoritos únicamente alcanzan los 56 Favoritos y las 8 fotos más comentadas solo han recibido un comentario por cada una de ellas. La cuenta no tiene marcados contenidos favoritos de otros autores ni se ha unido a ningún grupo. Dispone de 183 álbumes entre los que apenas hay alguno en blanco y negro y sus fotos son variadas (retratos, imágenes de ambiente y de situación en eventos y visitas para mostrar cercanía con la gente) y de calidad, aunque no abusan de recursos técnicos ni artísticos para transmitir sensación de realidad y alejarse de la manipulación. Los álbumes contienen imágenes de actos del partido, asistencia a eventos, convocatorias y actividades, como un acto de apoyo a JUSAPOL, una cenacoloquio con los colegiales del Colegio Mayor San Pablo CEU o entrevistas en medios como EsRadio. También los hay con personalidades famosas como Theresa Zabell, Joana Pastrana o la presentación de un libro de José María Finat.

Destacan especialmente los dedicados a sus líderes: Santiago Abascal (81 fotos), Javier Ortega (8 fotos) y Rocío Monasterio (10 fotos), Espinosa de los Monteros (12 fotos), Alicia Rubio (10 fotos), Mazaly Aguilar ( 9 fotos), José Antonio Ortega Lara (3 fotos).

Los álbumes tienen títulos muy largos a modo de titular informativo o consigna: Sí a la vida, Sí a la caza, España lo primero en Colón, Protesta contra Torra, Manifestación Caravana Fase Libertad, Frente a los proetarras en Alsasua, Juicio contra los golpistas, Manifestación en apoyo del turismo canario perjudicado por la inmigración ilegal, La España por venir o Cañas por España. Funciona a modo de repositorio de imágenes del partido que cualquiera puede consultar. 


\section{Youtube}

La cuenta de Youtube dispone de 8 listas de reproducción: Radios (1 vídeo), Los presupuestos de la ruina (5 vídeos), Moción de censura (21 vídeos), Crisis Nacional CORONAVIRUS (23 vídeos), VOX en Europa (3 vídeos), España Siempre (18 vídeos), Congreso (44 vídeos) y Fronteras seguras (4 vídeos). También hay cortes audiovisuales de programas de televisión en varias cadenas con apariciones de sus líderes y videocomunicados de figuras como Jorge Buxadé, Macarena Olona o Ignacio Garriga. Muchas piezas suelen contener los mejores momentos de los discursos, música épica, imágenes de la oposición y de gente en la calle protestando contra Vox en sus actos, para mostrarse como luchadores contra la adversidad.

A nivel técnico la gran mayoría de vídeos disponen de al menos un grafismo de cabecera -habitualmente de un diseño y calidad media alta-, mosca con la marca del partido, presencia de rótulos, infografías, chroma-key, discursos a cámara y apelaciones al espectador. También es común el uso de etiquetas como \#StopInvasiónMigratoria o \#PresupuestosDelaRuina y uso de emoticonos (especialmente el que simboliza fuerza y el de la bandera de España).

Imagen 2. Cuenta de Youtube de Vox. Fuente: Youtube

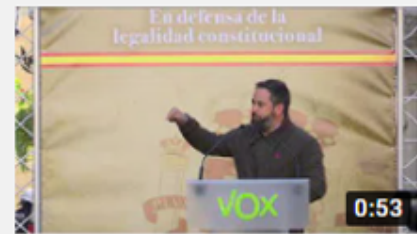

Santiago Abascal: "El mayor enemigo de la Constitución...

6185 visualizaciones . hace 4 dias

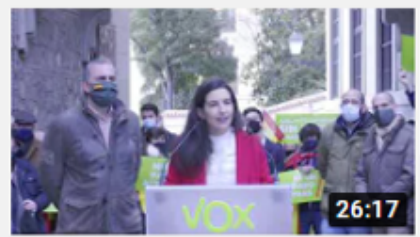

Acto en defensa de la legalidad constitucional en...

86.937 visualizaciones hace 4 dias

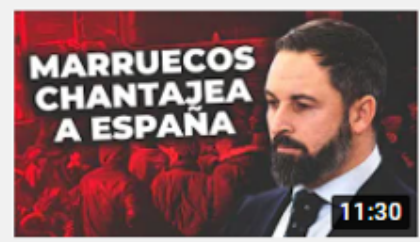

Entrevista a Santiago

Abascal sobre la avalancha...

128.921 visualizaciones . hace 6 dias

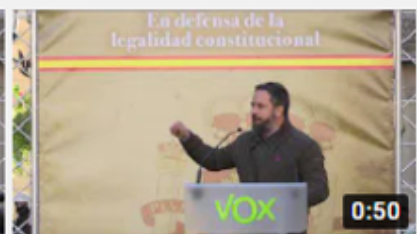

Santiago Abascal desvela el pacto de Zapatero con la ETA

14.897 visualizaciones . hace 4 dias

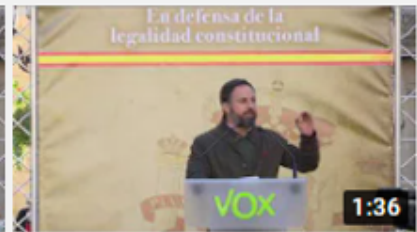

Santiago Abascal: "En las calles hay más respeto a la... 11.977 visualizaciones . hace 4 dias

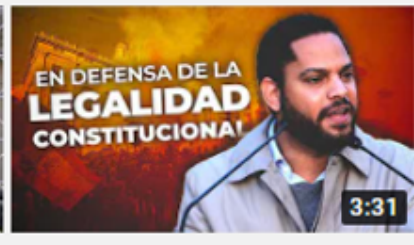

Ignacio Garriga lee el manifiesto en defensa de la... 10.958 visualizaciones . hace 4 dias
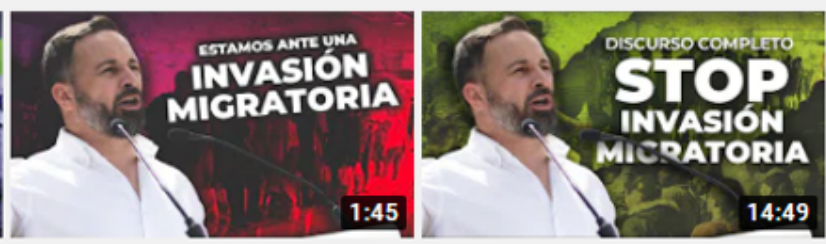

\#StoplnvasiónMigratoria | sos Canaria

\#StopInvasiónMigratoria | Discurso completo de...

27.623 visualizaciones . hace 4 dias

38.637 visualizaciones hace 5 días
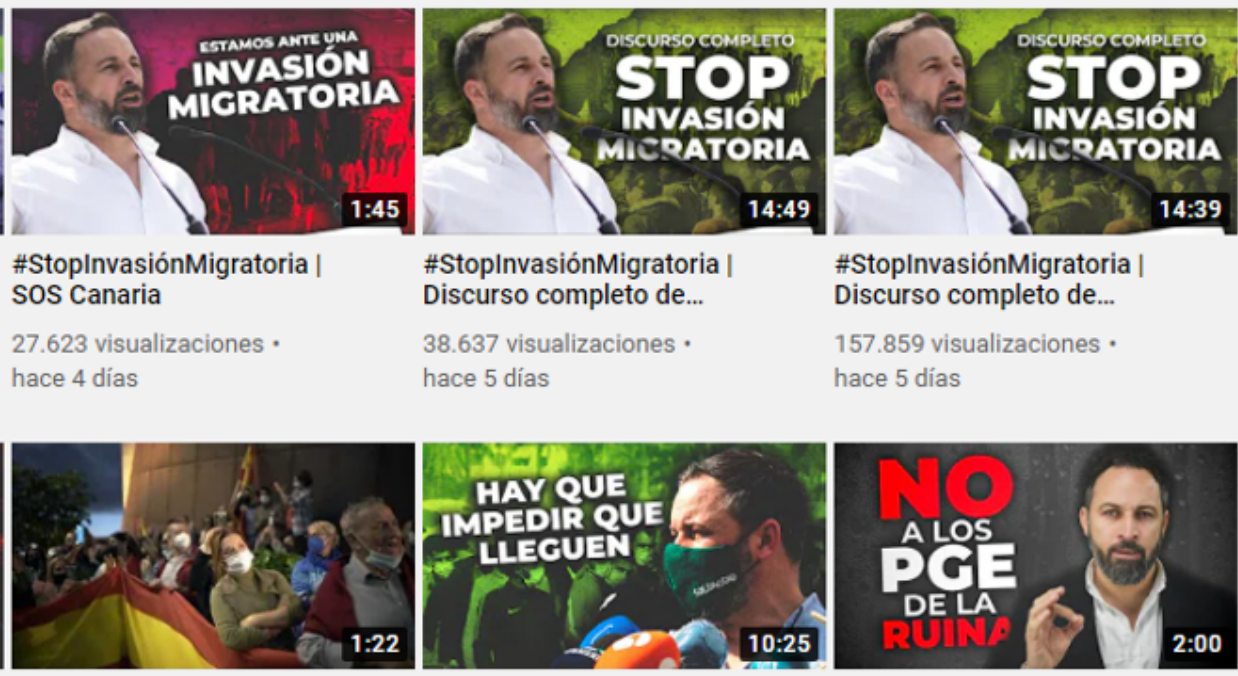

¡Con Vox, los extranjeros que asaltan nuestras fronteras $\mathrm{n}$... 80.534 visualizaciones . hace 1 semana

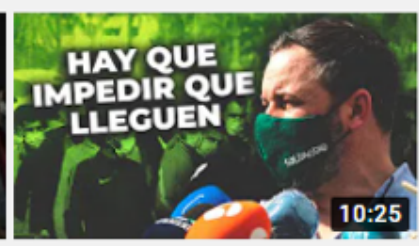

¡Santiago Abascal llega a Canarias para denunciar la... 163.426 visualizaciones . hace 1 semana

Telegram

El canal de Telegram lo emplean para difundir mensajes y noticias, con texto, vídeos y enlaces a los perfiles en el resto de redes sociales. Desde el 29 de julio de 2020 han producido 6 mensajes fijados y en ellos acumulan 169.000 visualizaciones. También 
dispone en la sección de archivos para descargar de un material PDF con el Acuerdo entre PP y Vox de enero de 2019.

\section{Instagram}

En Instagram disponen de cuenta verificada y en su bio incluyen las cuentas de varios de sus líderes: "Somos la España Viva $[\mathcal{E} \rightarrow$ @santi_abascal $\Rightarrow$ @javierortegasmith $\square$ @rociomonasteriovox $\Rightarrow$ @ivanedlm $\Rightarrow$ @jorge_buxade".

Cuentan con 278 vídeos en Instagram TV y de 1 reel consistente en un discurso de Abascal en el Congreso. Tienen 23 grupos de stories: citas, actos, entrevistas en medios, ruedas de prensa, elecciones, sede, algunas comunidades autónomas, Fase libertad, Moción de censura, Stop invasión, PGE de la ruina, TikTok y Congreso.

En su mayoría los contenidos son intervenciones de dirigentes del partido, bien en el Congreso, en actos de Vox, en programas de televisión o en vídeos corporativos. Tienen una fuerte presencia recursos habituales en esta red como rotulación, iconos, emoticonos, textos explicativos, enlaces y etiquetas que usan para cada campaña/programa. El lenguaje es similar al de otras redes, pero más desenfadado y con expresiones propias de la jerga de redes (como el famoso Thug Life), aunque se mantienen los términos bélicos, las metáforas, las descalificaciones y las llamadas a la acción.

Imagen 3. Publicación en Instagram de Vox. Fuente: Instagram
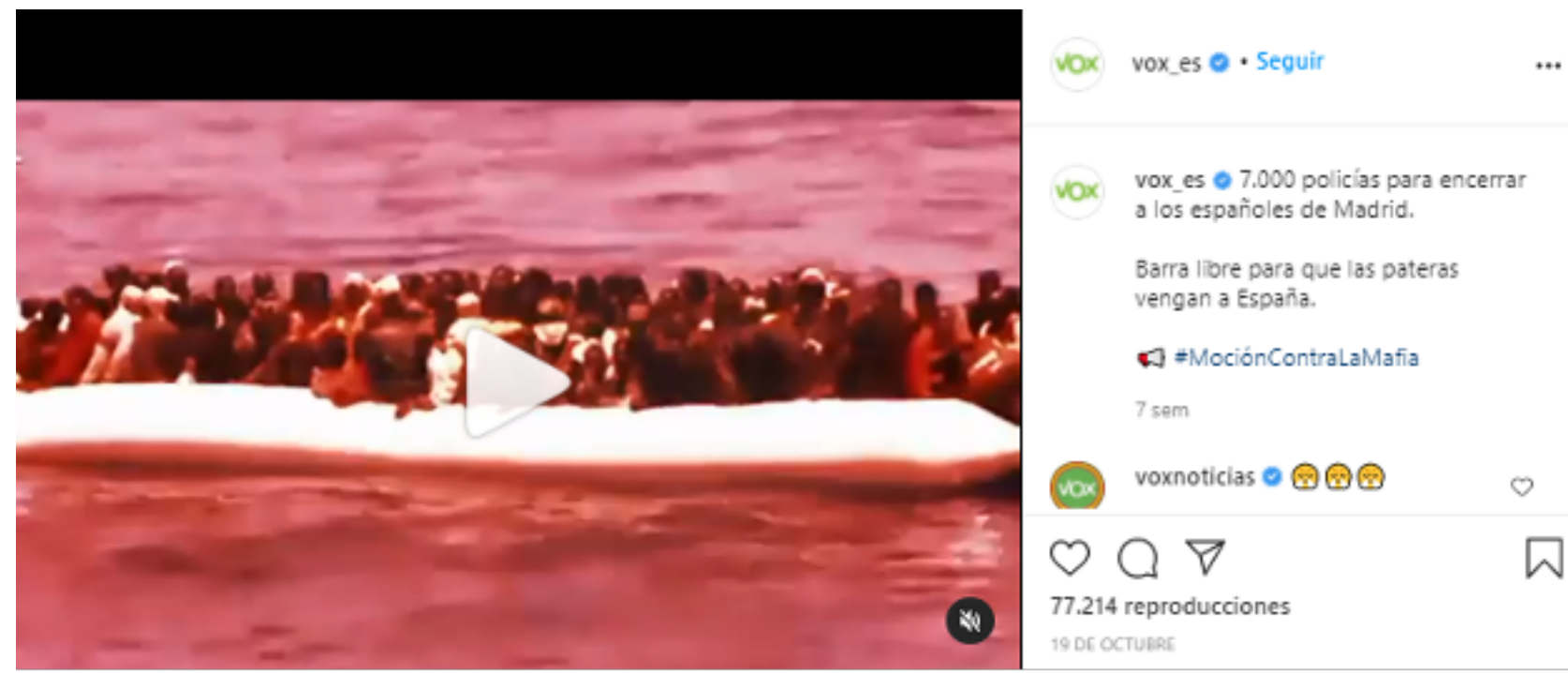

\section{TikTok}

TikTok es una red donde aún no han creado demasiado contenido, ya que comienzan a usarla en febrero de 2020 y hasta final de año únicamente han colgado 9 vídeos y los que le gustan a la cuenta de vox_espana están ocultos actualmente. Sin embargo, están registrando un gran éxito de seguimiento y de interacciones, ya que por ejemplo el hashtag vox_espana ha alcanzado los 12,4 millones de visualizaciones y sus variantes superan los 21,5 millones de visualizaciones. El contenido en esta red se ajusta a sus códigos visuales, con piezas de muy corta duración, música, contenido informal, mensajes claros, uso de emoticonos y efectos visuales, además de críticas y ridiculizaciones a sus oponentes (tabla 4). 
Tabla 4. Publicaciones de Vox en TikTok. Elaboración propia. Fuente: TikTok

\begin{tabular}{|c|c|c|c|c|}
\hline Texto & Like & $\begin{array}{l}\text { Comen- } \\
\text { tarios }\end{array}$ & $\begin{array}{l}\text { Com- } \\
\text { partir }\end{array}$ & Descripción del vídeo \\
\hline $\begin{array}{l}\text { ¡Abran paso Lácras, llegó el } \\
\text { Admin! bE A }\end{array}$ & $22.2 \mathrm{k}$ & 1554 & 6723 & $\begin{array}{l}\text { Abascal en el Congreso con extracto de un discurso. Uso de } \\
\text { filtro, rótulos, retroceso, audio del discurso y música. }\end{array}$ \\
\hline$\Leftrightarrow \theta=$ & $22.3 \mathrm{~K}$ & 866 & 2487 & $\begin{array}{l}\text { Chicas patinando, con los logos del PP y Ciudadanos por } \\
\text { cara, que se estrellan contra una puerta rotulada con el } \\
\text { nombre de Vox. Crítica y ridiculización a los adversarios } \\
\text { políticos. }\end{array}$ \\
\hline $\begin{array}{l}\text { P } \$ \text { D } \\
\text { pasta basta para convertir a } \\
\text { un progre en casta. }\end{array}$ & 3067 & 250 & 184 & $\begin{array}{l}\text { Vídeo con cortes de Irene Montero donde se la ridiculiza. } \\
\text { Audios y discursos de ella, fotos posando en revistas de } \\
\text { moda y vídeo filtrado. Música. }\end{array}$ \\
\hline $\begin{array}{l}\text { Santiago Abascal señala } \\
\text { a Pedro Sánchez y Pablo } \\
\text { Iglesias: "Sois culpables" } \\
\text { \#VOX \#SantiagoAbascal } \\
\text { \#España \#VivaEspaña }\end{array}$ & $27.4 \mathrm{~K}$ & 3751 & 4976 & $\begin{array}{l}\text { Discurso de Abascal culpando al 8M del Covid-19. Uso de } \\
\text { rótulos. }\end{array}$ \\
\hline $\begin{array}{l}\text { Santiago Abascal } \\
\text { retrata al Gobierno del } \\
\text { bulo y la miseria.\#VOX \# } \\
\text { Santiagoabascal \# España \# } \\
\text { VivaEspaña }\end{array}$ & 7711 & 1183 & 590 & $\begin{array}{l}\text { Discurso de Abascal sobre la moción de censura y atacando } \\
\text { al PP. Uso de rótulos discurso y música épica. Cierre con el } \\
\text { logo Vox. }\end{array}$ \\
\hline $\begin{array}{l}\text { \#ت̃ \#VOX \#VivaEspaña } \\
\text { \#España }\end{array}$ & 9767 & 1556 & 1281 & $\begin{array}{l}\text { Vídeo de chico con la bandera de España en la muñeca } \\
\text { hablando por Whatsapp con una chica. Ella le dice que va a } \\
\text { ir al mitin de Vistalegre y entra rótulo "Cuando sabes que es } \\
\text { la tuya". El chico hace el gesto de ok con las manos. Empleo } \\
\text { de música electrónica y emoticonos. }\end{array}$ \\
\hline $\begin{array}{l}\text { ¡Te esperamos este } \\
\text { domingo en Vistalegre! } \\
\text { \#VOX \#España } \\
\text { \#quevivaespaña } \\
\text { \#VivaEspaña }\end{array}$ & 5750 & 1051 & 177 & $\begin{array}{l}\text { Llamamiento de Ortega Smith a los jóvenes para acudir a } \\
\text { Vistalegre: "Eres joven y español. Y por eso eres rebelde; y } \\
\text { por eso amas a tu patria; y por eso este domingo a partir de } \\
\text { las } 10 \text { tienes que estar aquí en Vistalegre para demostrar } \\
\text { que en tus venas llevas lo mejor de un pasado y la } \\
\text { esperanza de un futuro. De tí depende la alternativa, tienes } \\
\text { que ser la vanguardia que demuestre que la España viva, la } \\
\text { España valiente, que la España que no se rinde. Está en tus } \\
\text { manos. Ven aquí a defenderla con nosotros. Este domingo } \\
\text { te espero en Vistalegre”. Emplea rótulos y cierre con marca } \\
\text { del partido y música épica. }\end{array}$ \\
\hline $\begin{array}{l}\text { ¡Acude a Vistalegre! } 8 \\
\text { de marzo a las 12:00 } \\
\text { \#VivaEspaña \#VOX } \\
\text { \#Vistalegre }\end{array}$ & 6165 & 1099 & 267 & $\begin{array}{l}\text { Aparecen los textos de ‘Comportaos sin miedo' (etiqueta) } \\
\text { y'Tiranía izquierdista'. Imágenes de gente apoyando a Vox } \\
\text { en Vistalegre I. Discurso de Abascal y acompañamiento de } \\
\text { música épica. }\end{array}$ \\
\hline $\begin{array}{l}\text { Ya estamos aquí } \mathbb{Z} \\
\text { \#VOX \#España \#VivaEspaña } \\
\text { \#SantiagoAbascal }\end{array}$ & $25.6 \mathrm{~K}$ & 3707 & 4495 & $\begin{array}{l}\text { Vídeo entrando en el despacho de Abascal. Emplea música } \\
\text { rock conocida, rótulos de cuenta atrás y start (con estética } \\
\text { de videojuego). Abascal mira en su móvil un vídeo de TikTok } \\
\text { donde salen jóvenes, chicas con la bandera de España. Y el } \\
\text { rótulo "Ya estamos aquí" acompañado del brazo de fuerza y } \\
\text { la bandera española. }\end{array}$ \\
\hline
\end{tabular}

\section{Gab}

En Gab Vox es un miembro PRO de la red social y ha publicados 122 fotos, la mayoría en forma de poster o gráfica con extractos de su argumentario o proclamas, 22 son de miembros de la ejecutiva y algunas imágenes que muestran el apoyo de su masa social. No dispone de vídeos propios, ya que los subidos a la cuenta son enlaces a otros soportes. Retootea abundante contenido de otros usuarios. Al principio se produjo un nivel muy alto de interactividad con las primeras publicaciones, pero después ha ido disminuyendo hasta apenas alcanzar unas decenas. En cuanto a la sección comentarios 
Imagen 4. Cuenta de TikTok de Vox. Fuente: TikTok

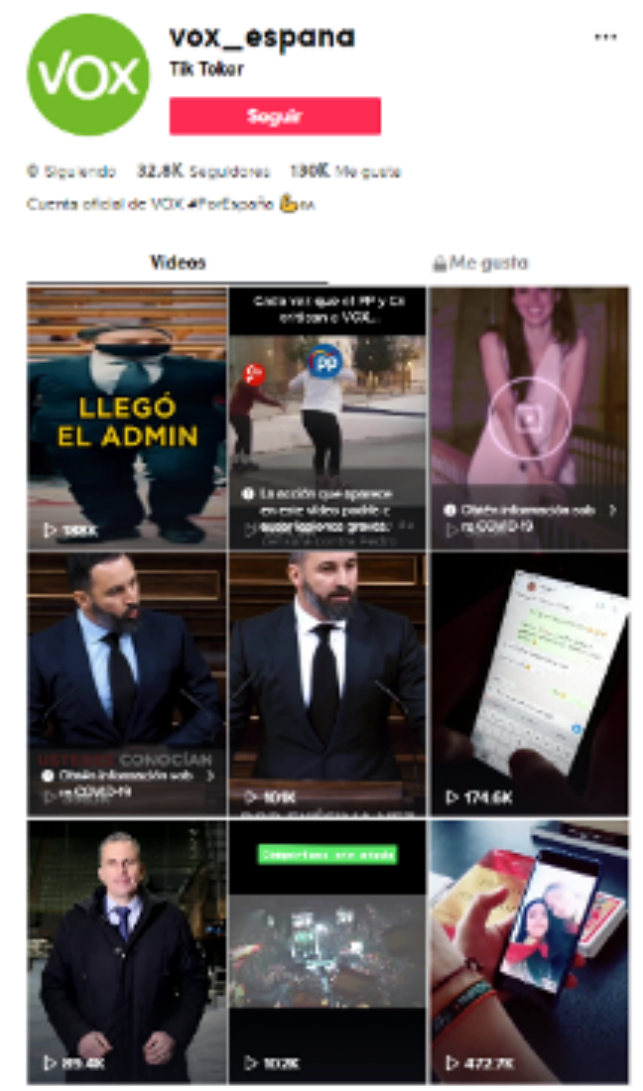

aparecen donde la cuenta ha comentado, que son normalmente publicaciones de otros usuarios.

Enlaspublicaciones primael contenido multimedia, con gran cantidad de enlaces a fuera de la red, noticias principalmente de OKDiario y enlaces a cortes de intervenciones de los miembros de su ejecutiva en medios de comunicación. También hay abundante contenido que da cobertura a sus actos propios, como la manifestación contra el Gobierno, y destinado a verter alabanzas hacia sus líderes, en especial hacia Abascal: “Has conseguido que millones de españoles no se sientan solos en la lucha por la defensa de España y su libertad frente al totalitarismo progre y separatista, convirtiendo a VOX en la tercera fuerza política. \#AbascalOrgulloNacional "₹्ञ"

También contiene bastante contenido en el que ataca directamente los posicionamientos del Partido Popular y en el que se alinea con la extrema derecha estadounidense en asuntos como el Black Lives Matter o las críticas a Soros y la conspiración del Coronavirus.

Imagen 5. Cuenta de Gab de Vox. Fuente: Gab
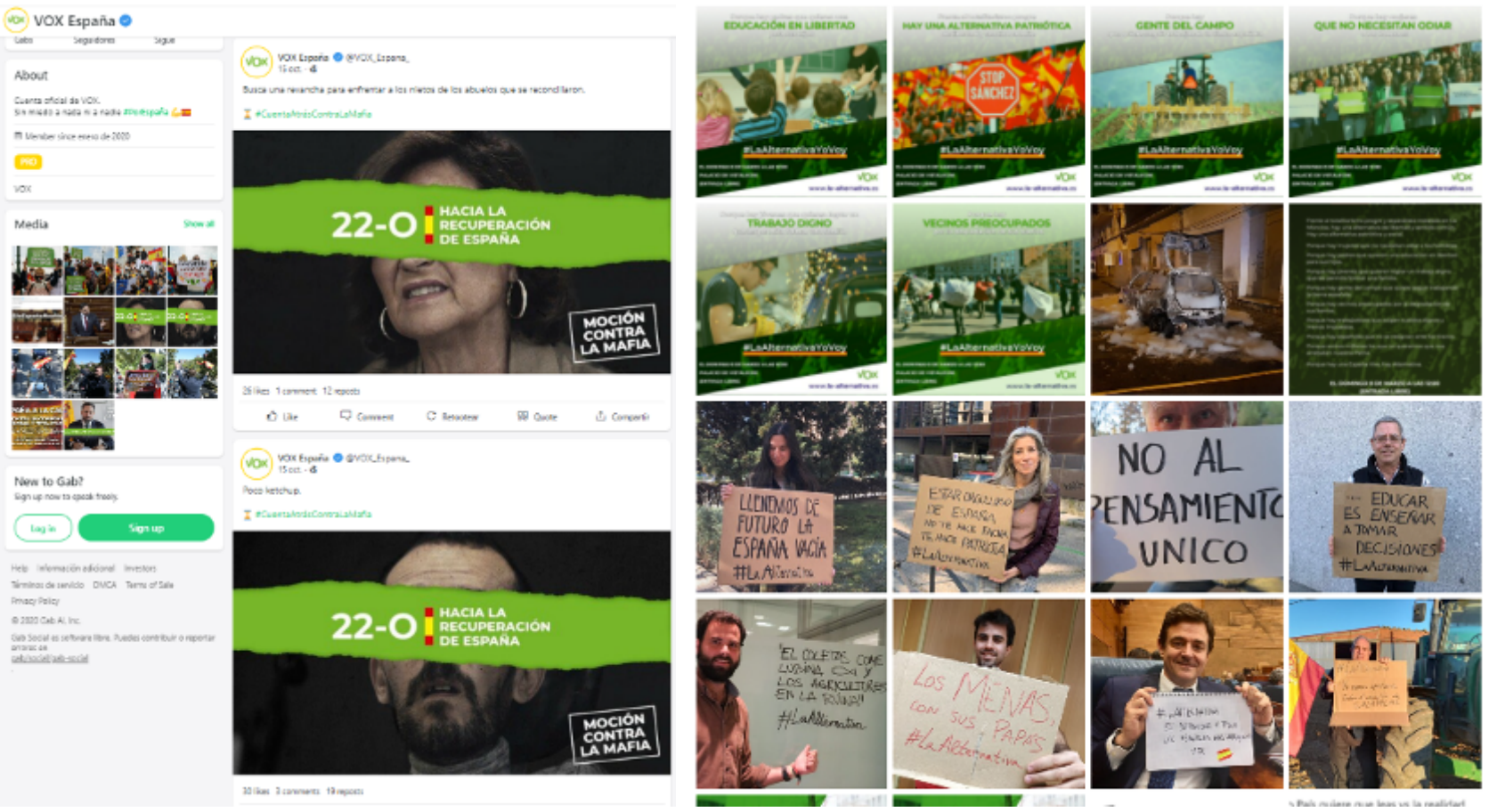

A continuación, se incluyen diversos ejemplos de publicaciones en las distintas redes sociales, por su potencial ilustrativo de la acción comunicativa de Vox (tabla 5). 
Tabla 5. Ejemplos de publicaciones de Vox en redes sociales. Elaboración propia. Fuente: Facebook, Twitter, Youtube, Instagram, Gab.

\begin{tabular}{|c|c|}
\hline Red & Ejemplos de publicaciones \\
\hline Facebook & 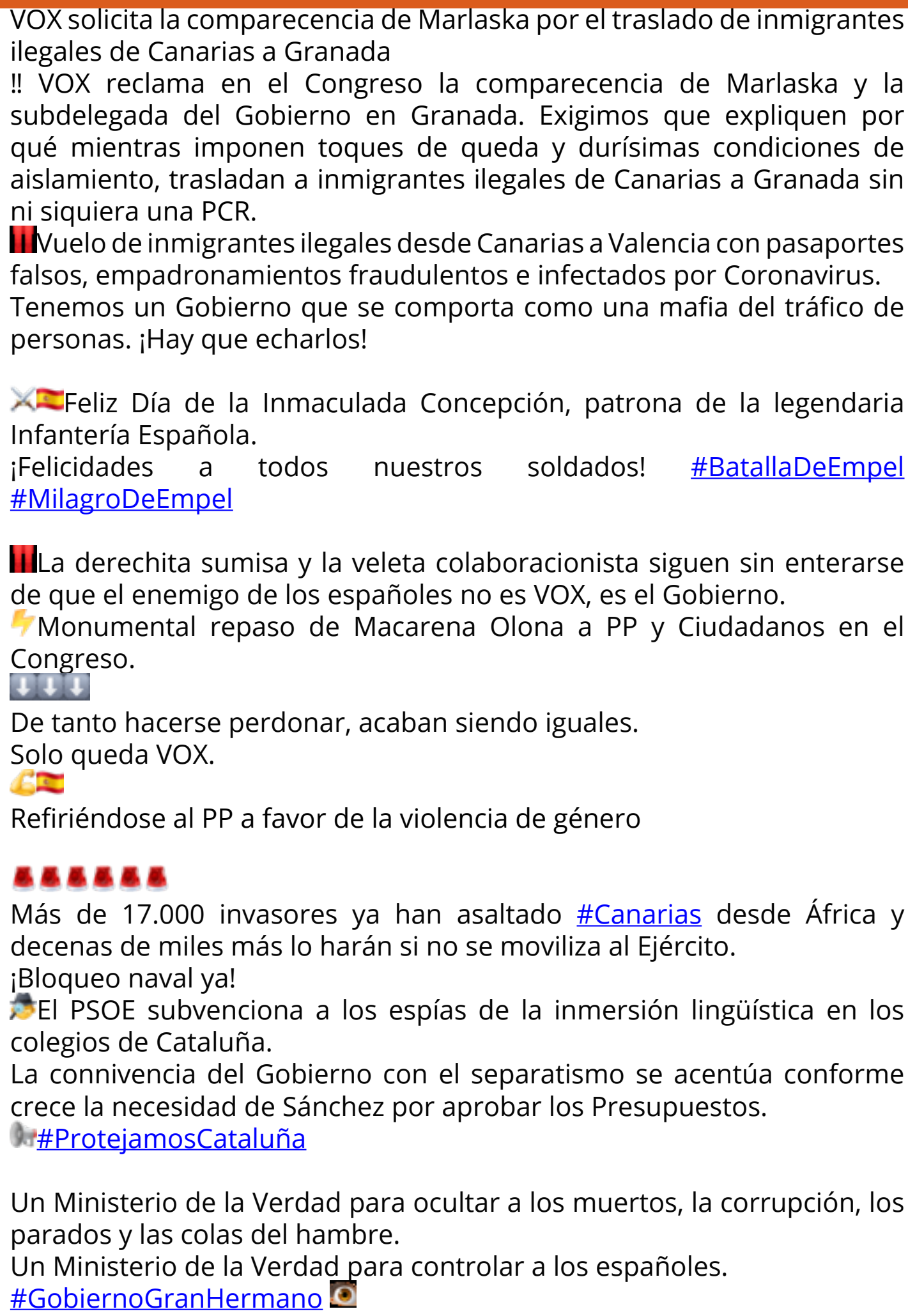 \\
\hline
\end{tabular}




\begin{tabular}{|l|l|}
\hline \multirow{7}{*}{ ¿Cómo ser afiliado? } \\
Twitter \\
La trama (para referirse al Gobierno). \\
Criminalizar a un sector inocente implica: \\
SOS EPérdida de empleos \\
SOS GHambre \\
SOS GRuina \\
SOS GMiseria \\
Si un gobierno te quita lo que es tuyo por derecho, está literalmente \\
atentando contra tu libertad y destruyendo todo por lo que has luchado. \\
\#SOSHosteleria \\
(Dorso de la mano con el dedo índice señalando hacia abajo) No estáis \\
Solos (Dorso de la mano con el dedo índice señalando hacia abajo)
\end{tabular}




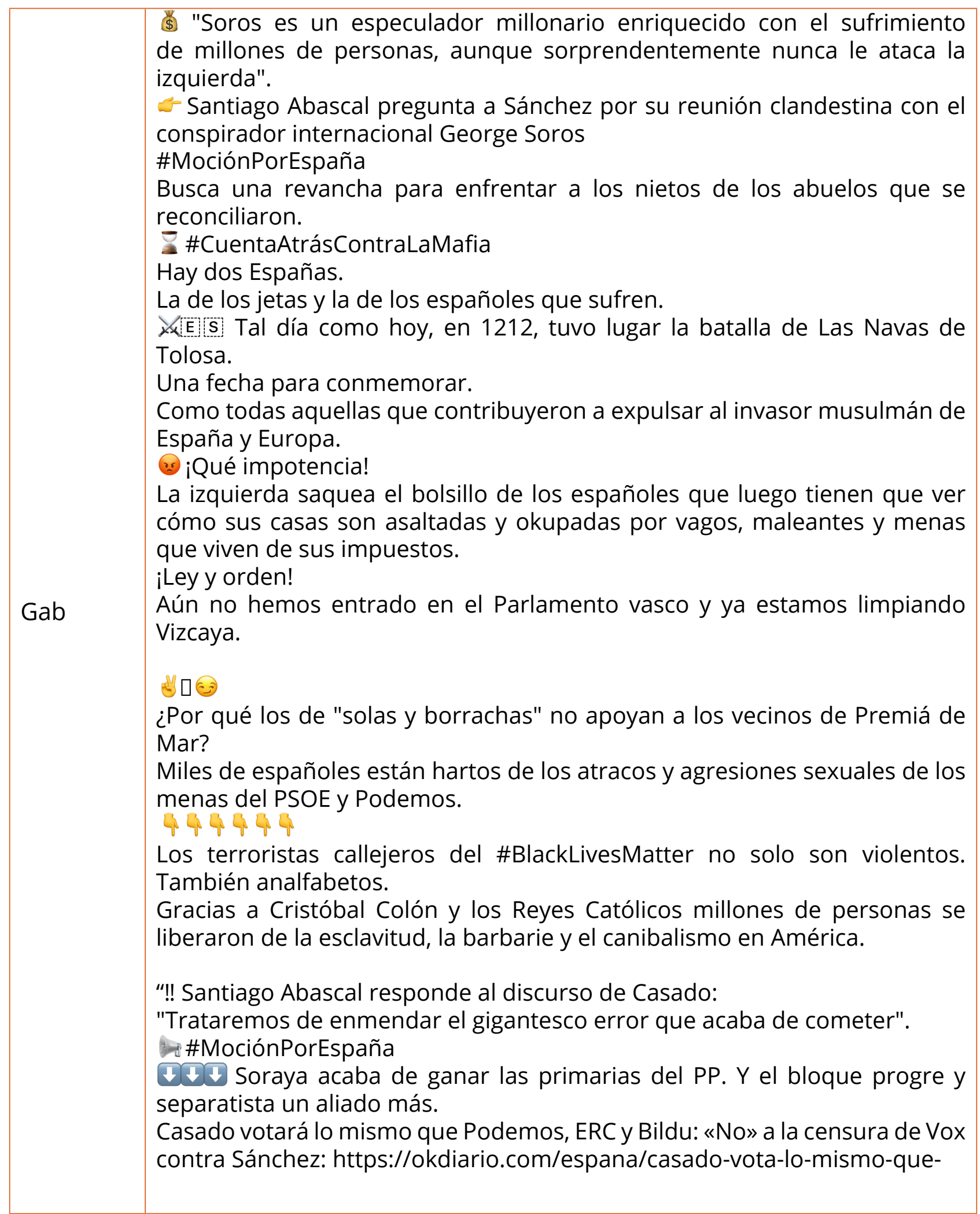

\section{Discusión y conclusiones}

En el rápidamente cambiante mundo de la política digital las redes sociales son imprescindibles para alcanzar al público más joven y al que no se siente vinculado a los medios convencionales. Vox ha sabido aprovecharlas para movilizar a sus simpatizantes e intentar influir en la agenda y en el framing (López y Vicente, 2013) a través del consumo online de politainment (Berrocal-Gonzalo, Campos-Domínguez y Redondo-García, 2014) por parte de una gran comunidad de usuarios. Así, aunque a veces no interactúen en 
exceso, se han fidelizado y difunden el mensaje del partido (Pallarés y Ortega, 2017). Esta investigación ha logrado sus objetivos al analizar la estrategia de Vox en redes sociales, determinar los elementos que utiliza en el contexto digital y que componen su identidad, identificar los distintos recursos en los que basan sus publicaciones y caracterizar los contenidos que la formación produce en redes sociales para conformar su estrategia comunicativa y movilizar a su público.

Queda patente el hiperliderazgo de Santiago Abascal, destacando su figura, imagen y trayectoria, coincidiendo con lo señalado por estudios previos (Aladro y Requeijo, 2020), aunque también se potencia la de otras caras visibles del partido. Se da peso a las mujeres de la ejecutiva y en las imágenes de público y simpatizantes es habitual que salgan chicas jóvenes.

A nivel discursivo Vox emplea argumentos emocionales, apelando a sentimientos como el miedo (principalmente a la inmigración y al comunismo o posicionamientos políticos de izquierdas) y el hartazgo hacia la clase política. Identifica claramente a sus enemigos (prensa, adversarios políticos, inmigrantes) y fija en ellos sus críticas, descalificaciones y ridiculizaciones. Aplica un lenguaje belicista y de exaltación del sentimiento patriótico y de pertenencia que combina con estrategias visuales propias de las redes sociales, tanto en los formatos (imágenes, vídeos breves) como en la aplicación de elementos como filtros, efectos, cabeceras, emoticonos o memes. El ideario se presenta de manera clara y explícita, a través de construcciones simples que reflejan posicionamientos clave en el argumentario del partido. A través de esta construcción narrativa digital y de la amplificación de su autorrepresentación impacta de forma atractiva en el público a través de contenidos polémicos y directos, pero con planteamientos muy simplificados.

De este modo combina un posicionamiento ideológico de extrema derecha o derecha radical con una estrategia populista, en la línea de lo indicado por autores como Mudde y Rovira (2018), para visibilizar y difundir sus mensajes, coincidiendo con lo que ya han señalado estudios previos sobre populismo y redes sociales como los de Engesser et al. (2017).

Es muy significativo el uso de diversas redes sociales para alcanzar nuevos segmentos de posibles votantes, en especial las destinadas a los jóvenes como TikTok, Instagram y Youtube. También resulta de gran relevancia el uso de Gab donde, por su enfoque y público vinculado a la extrema derecha, el discurso de Vox deja de centrarse en el Gobierno o en Podemos para atacar directa y claramente al Partido Popular, pues es con quien puede disputar audiencia en esa plataforma. Gab funciona como una cámara de eco (Barberá et al., 2015) donde la homofilia (Lozares y Verd, 2012) está claramente presente.

El uso de las redes sociales en la comunicación política y en especial de las nuevas plataformas puede ayudar a comprender los procesos de polarización y vinculación sentimental con ciertos posicionamientos que afectan a la sociedad, así como contribuir a detectar estrategias para luchar contra la desinformación y los contenidos abusivos.

Las limitaciones de esta investigación son las propias de un estudio de caso, así como las derivadas de conformarse como una radiografía de un periodo temporal concreto sobre un fenómeno en continua evolución. Sin embargo, se trata de un campo de estudio de gran interés, tanto en el contexto español como en el internacional. Se pueden abordar futuras líneas de investigación centradas en cuestiones como la evolución de las estrategias de la derecha radical en redes sociales relativamente recientes, como 
TikTok y Gab, la creación de contenidos al servicio del populismo o las implicaciones de fenómenos como la espectacularización de la política, las cámaras de eco o las burbujas filtro y su influencia en el sistema mediático convencional.

\section{REFERENCIAS}

Aguado, J. M., Feijóo, C. y Martínez, I. J. (2014): “El impacto del ecosistema móvil en las industrias culturales", en TELOS, Revista de pensamiento sobre comunicación, tecnología y sociedad, n 99, pp. 136-144.

Aladro Vico, E. y Requeijo Rey, P. (2020): “Discurso, estrategias e interacciones de Vox en su cuenta oficial de Instagram en las elecciones del 28-A. Derecha radical y redes sociales", en Revista Latina de Comunicación Social, 77, pp. 203-229. Disponible en Internet: https://www. doi.org/10.4185/RLCS-2020-1455 [Consulta: 1 de Diciembre de 2020]

Alfonso Sánchez, I. y Fernández Valdés, M. (2020): “Comportamiento informacional, infodemia y desinformación durante la pandemia de COVID-19", en Anales De La Academia De Ciencias De Cuba, 10(2), e882. Disponible en Internet: http://www.revistaccuba.sld.cu/index.php/revacc/ article/view/882/889 [Consulta: 25 de Noviembre de 2020]

Allahverdipour, H. (2020): "Global Challenge of Health Communication: Infodemia in the Coronavirus Disease (COVID-19) Pandemic", en J Educ Community Health,7(2), pp. 65-67. Disponible en Internet: URL:http://jech.umsha.ac.ir/article-1-1000-en.html [Consulta: 7 de Diciembre de 2020]

Alonso, M. (2015): “Podemos: el ciberactivismo ciudadano llega a la política europea”, en Dígitos. Revista de Comunicación Digital, 1, pp. 91-110. Disponible en Internet: https://revistadigitos. com/index.php/digitos/article/view/5 [Consulta: 11 de Noviembre de 2020]

Amado, A. y Tarullo, R. (2015): “Tuitear para agendar: el uso de Twitter como gacetilla de prensa en la comunicación gubernamental", en Revista mexicana de opinión pública, (19), pp. 127145. Disponible en Internet: https://doi.org/10.1016/j.rmop.2015.02.003 [Consulta: 22 de Noviembre de 2020]

Aruguete, N. (2017): "The agenda setting hypothesis in the new media environment", en Comunicación y Sociedad, 28, pp. 35-58. Disponible en Internet: http://www. comunicacionysociedad.cucsh.udg. mx/index.php/comsoc/article/view/2929/5667 [Consulta: 15 de Noviembre de 2020]

Ballesteros Herencia, C. (2020):“La propagación digital del coronavirus: Midiendo el engagement del entretenimiento en la red social emergente TikTok", en Revista Española de Comunicación en Salud, 0, pp. 171-185. Disponible en Internet: http://dx.doi.org/10.20318/recs.2020.5459 [Consulta: 26 de Noviembre de 2020]

Barberá, P. et al. (2015): “Tweeting From Left to Right: Is Online Political Communication More Than an Echo Chamber?", en Psychological Science, 26(10), pp. 1531-1542. Disponible en Internet: https://doi.org/10.1177/0956797615594620 [Consulta: 26 de Noviembre de 2020]

Baviera, T. (2017): “Técnicas para el Análisis de Sentimiento en Twitter: Aprendizaje Automático Supervisado y SentiStrength", en Revista Dígitos, 1(3), pp. 33-50. Disponible en Internet: https:// revistadigitos.com/index.php/digitos/article/view/74 [Consulta: 1 de Noviembre de 2020]

Berrocal-Gonzalo, S., Campos-Domínguez, E. y Redondo-García, M. (2014): “Prosumidores mediáticos en la comunicación política: el «politainment» en YouTube", en Comunicar: Revista Científica de Comunicación y Educación, 22(43), pp. 65-72. Disponible en Internet: http://dx.doi. org/10.3916/C43-2014-06 [Consulta: 6 de Noviembre de 2020]

Capoano, E. (2018): “Innovación en medios independientes digitales: casos en Brasil y España”, 
en Mediatika. Cuadernos de Medios de Comunicación, (16), pp. 73-90. Disponible en Internet: http://ojs.eusko-ikaskuntza.eus/index.php/mediatika/article/view/149 [Consulta: 4 de Octubre de 2020]

Castells, M. (2001): La Galaxia Internet: reflexiones sobre Internet, empresa y sociedad. Barcelona: Plaza \& Janés.

Cebrián Herreros, M. (2008): “La Web 2.0 como red social de comunicación e información", en Estudios Sobre El Mensaje Periodístico, 14, pp. 345 - 361. Disponible en Internet: https:// revistas.ucm.es/index.php/ESMP/article/view/ESMP0808110345A [Consulta: 6 de Octubre de 2020]

Colleoni, E., Rozza, A. y Arvidsson, A. (2014): “Echo chamber or public sphere? Predicting political orientation and measuring political homophily in Twitter using big data", en Journal of communication, 64(2), pp. 317-332. Disponible en Internet: https://doi.org/10.1111/ jcom.12084 [Consulta: 2 de Diciembre de 2020]

Cotarelo, R. (Coord.). (2013): Ciberpolítica. Las nuevas formas de acción y comunicación políticas. Valencia: Tirant Humanidades.

Corellano, J. (23 de enero de 2020): “Twitter bloquea la cuenta oficial de Vox por "incitación al odio'"', en Público. Disponible en Internet: https://www.publico.es/politica/twitter-suspendecuenta-oficial-vox-incitacion-odio.html [Consulta: 2 de Octubre de 2020]

Daniels, J. (2018): “The algorithmic rise of the "alt-right"', en Contexts, 17(1), pp. 60-65. Disponible en Internet: https://doi.org/10.1177/1536504218766547 [Consulta: 30 de Octubre de 2020]

de Aguilera, M. y Casero, A. (2018): ¿Tecnologías para la transformación? Los medios sociales ante el cambio político y social, en Icono 14, 16 (1), pp. 1-21. Disponible en Internet: https:// doi.org/10.7195/ri14.v16i1.1162 [Consulta: 26 de Octubre de 2020]

Ekman, M. y Widholm, A. (2017): "Political communication in an age of visual connectivity: Exploring Instagram practices among Swedish politicians", en Northern lights: Film \& media studies yearbook, 15(1). Disponible en Internet: https://doi.org/10.1177/1745691619868208 [Consulta: 3 de Noviembre de 2020]

Engesser, S., Ernst, N., Esser, F. y Büchel, F. (2017): “Populism and social media: how politicians spread a fragmented ideology". Information, Communication \& Society, 20(8), pp. 1109-1126. https://www.doi.org/10.1080/1369118X.2016.1207697 [Consulta: 15 de abril de 2021]

Fontaneda, J. L. y Sánchez-Vítores, I. (2018): “La desafección en las urnas: las elecciones generales de 2015 en España", en Reis, 161, pp. 41-62. Disponible en Internet: http://www.jstor.org/ stable/44841756 [Consulta: 28 de Noviembre de 2020]

Forscher, P. S. y Kteily, N. S. (2020): "A psychological profile of the alt-right", en Perspectives on Psychological Science, 15(1), pp. 90-116. Disponible en Internet: https://doi. org/10.1177/1745691619868208 [Consulta: 1 de Diciembre de 2020]

Freitas, C. y Castro, C. (2010): "Narrativas audiovisuales y tecnologías interactivas", en Revista Estudios Culturales, (5), pp. 19-42. Disponible en Internet: https://dialnet.unirioja.es/servlet/ articulo?codigo=3739970 [Consulta: 11 de Noviembre de 2020]

Guinaudeau, B., Vottax, F. y Munger, K. (2020): “Fifteen Seconds of Fame: TikTok and the Democratization of Mobile Video on Social Media". Unpublished paper. Disponible en Internet: https://osf.io/f7ehq/download [Consulta: 7 de Diciembre de 2020]

Hendricks, J. A. y Denton, R. E. (Eds.) (2010): Communicator-in-chief. How Barack Obama used new media technology to win the White House. Playmouth: Lexington Books.

Herrero-Curiel, E. (2011): “El periodismo en el siglo de las redes sociales”, en Vivat Academia, 117E, 
pp. 1113-1128. Disponible en Internet: https://doi.org/10.15178/va.2011.117E.1113-1128 [Consulta: 1 de Octubre de 2020]

Hootsuite (2020). Digital 2020. Global Digital Overview. Hootsuite. Disponible en Internet: https://wearesocial.com/digital-2020 [Consulta: 2 de Diciembre de 2020]

Hütt Herrera, H. (2012): "Las redes sociales: una nueva herramienta de difusión”, en Revista reflexiones, 91(2). Disponible en Internet: https://revistas.ucr.ac.cr/index.php/reflexiones/ article/view/1513/1521 [Consulta: 16 de Octubre de 2020]

IAB Spain (2020): Estudio de redes sociales 2020. IAB Spain. Disponible en Internet https:// iabspain.es/estudio/estudio-redes-sociales-2020/ [Consulta: 6 d Diciembre de 2020]

Instituto Nacional de Estadística (INE) (2019): Encuesta sobre Equipamiento y Uso de Tecnologías de Información y Comunicación en los Hogares. Año 2019. Instituto Nacional de Estadística (INE). Disponible en Internet: https://www.ine.es/uc/dl3NRnMU [Consulta: 9 de Diciembre de 2020]

Kalmar, I., Stevens, C. y Worby, N. (2018): "Twitter, Gab, and Racism: The Case of the Soros Myth", en Proceedings of the 9th International Conference on Social Media and Society (SMSociety '18). Association for Computing Machinery, New York, 330-334. Disponible en Internet: https:// doi.org/10.1145/3217804.3217939 [Consulta: 1 de Diciembre de 2020]

Lalancette, M. y Raynauld, V. (2019): “The Power of Political Image: Justin Trudeau, Instagram, and Celebrity Politics", en American Behavioral Scientist, 63(7), pp. 888-924. Disponible en Internet: https://doi.org/10.1177/0002764217744838 [Consulta: 9 de Noviembre de 2020]

Liebhart, K., y Bernhardt, P. (2017): “Political Storytelling on Instagram: Key Aspects of Alexander Van der Bellen's Successful 2016 Presidential Election Campaign", en Media and Communication, 5(4), pp. 15-25. Disponible en Internet: http://dx.doi.org/10.17645/mac.v5i4.1062 [Consulta: 18 de Noviembre de 2020]

Lima, L., Reis, J. C., Melo, P., Murai, F., Araujo, L., Vikatos, P., y Benevenuto, F. (2018): “Inside the right-leaning echo chambers: Characterizing gab, an unmoderated social system", en 2018 IEEE/ACM International Conference on Advances in Social Networks Analysis and Mining (ASONAM), pp. 515-522. IEEE. Disponible en Internet: https://ieeexplore.ieee.org/document/8508809 [Consulta: 27 de Noviembre de 2020]

López-García, G. (2016): “'Nuevos' y 'viejos' liderazgos: la campaña de las elecciones generales españolas de 2015 en Twitter", en Communication\&Society, 29(3), pp. 149-167. Disponible en Internet: https://doi.org/10.15581/003.29.3.149-168 [Consulta: 20 de Noviembre de 2020]

López Rabadán, P., y Vicente Mariño, M. (2013): “Propuestas de consolidación teórica y analítica para los estudios de framing en la investigación sobre comunicación política", en Sanders, K., Canel, M. J., Capdevila, A. y Gurrionero, M. G.: Estudios de Comunicación Política. Madrid: Tecnos, pp. 239-259.

Lotero-Echeverri, G., Romero-Rodríguez, L. M. y Pérez-Rodríguez, M. A. (2018): “Fact-checking vs. Fake news: Periodismo de confirmación como componente de la competencia mediática contra la desinformación", en index.comunicación, 8(2), pp. 295-316. Disponible en Internet: https://journals.sfu.ca/indexcomunicacion/index.php/indexcomunicacion/article/ view/370/400 [Consulta: 4 de Noviembre de 2020]

Lozares Colina, C. y Verd J. M. (2012): “De la homofilia a la cohesión social y viceversa”, en Redes. Revista Hispana Para El análisis De Redes Sociales, 20, pp. 29-50. Disponible en Internet: https:// www.raco.cat/index.php/Redes/article/view/249747 [Consulta: 9 de Noviembre de 2020]

Magallón, R. (2020). La nueva infonormalidad: no pienses en 'fake news', piensa en desinformación. Cuadernos de Periodistas, 40. Disponible en Internet: http://www. 
cuadernosdeperiodistas.com/la-nueva-infonormalidad-no-pienses-en-fake-news-piensa-endesinformacion/ [Consulta: 5 de Diciembre de 2020]

Main, T. J. (2018): The rise of the alt-right. Ebook: Brookings Institution Press.

Martín Cubas, J., Soria-Olivas, E., Llosa Guillén, Á. y Buendía Ramón, V. (2020): “La agenda building de los partidos políticos españoles en las redes sociales: Un análisis de Big data". En Revista Dígitos, 1(6), pp. 253-274.

Min Baek, Y. (2015): "Political mobilization through social network sites: The mobilizing power of political messages received from SNS friends", en Computers in Human Behavior, 44, pp. 1219. Disponible en Internet: https://doi.org/10.1016/j.chb.2014.11.021[Consulta: 2 de Octubre de 2020]

Morán, M. L. y Benedicto, J. (2016): “Los jóvenes españoles entre la indignación y la desafección política: una interpretación desde las identidades ciudadanas", en Última década, 24(44), pp. 11-38. Disponible en Internet: https://dx.doi.org/10.4067/S0718-22362016000100002 [Consulta: 8 de Noviembre de 2020]

Mudde, C. y Rovira Kaltwasser, C. (2018): "Studying populism in comparative perspective: Reflections on the contemporary and future research agenda". Comparative Political Studies, 51(13), pp. 1667-1693. https://doi.org/10.1177/0010414018789490 [Consulta: 9 de abril de 2020]

Nulty, P., Theocharis, Y., Popa, S. A., Parnet, O. y Benoit, K. (2016): “Social media and political communication in the 2014 elections to the European Parliament", en Electoral studies, 44, pp. 429-444. Disponible en Internet: https://doi.org/10.1016/j.electstud.2016.04.014 [Consulta: 2 de Noviembre de 2020]

Observatorio Nacional de las Telecomunicaciones y la Sociedad de la Información (2019): Informe Anual 2018 "La Sociedad en Red". Transformación digital en España (Edición 2019). Ministerio de Asuntos Económicos y Transformación Digital Gobierno de España. Disponible en Internet: https://www.ontsi.red.es/es/estudios-e-informes/Informes-anuales/Informe-Anual2018-La-Sociedad-en-Red-Transformacion-digital [Consulta: 14 de Noviembre de 2020]

Orejuela, S. (2009): “Personalización política: la imagen del político como estrategia

Electoral", en Revista de Comunicación, 8(61), pp. 60-84. Disponible en Internet: http://udep.edu. pe/comunicacion/rcom/pdf/2009/Art060-83.pdf [Consulta: 2 de Noviembre de 2020]

Pallarés Navarro, S. y García Ortega, C. (2017): “Análisis comparativo del discurso de Mariano Rajoy en Twitter durante las dos campañas electorales de 2015: las autonómicas del 24M y las generales del 20D", en Revista Dígitos, 1(3), pp. 119-136. Disponible en Internet: https:// revistadigitos.com/index.php/digitos/article/view/82 [Consulta: 10 de Noviembre de 2020]

Parmelee, J. H. y Roman, N. (2019): “Insta-Politicos: Motivations for following political leaders on Instagram, en Social Media + Society, pp. 1-12. Disponible en Internet: https://doi. org/10.1177/2056305119837662 [Consulta: 5 de Noviembre de 2020]

Puentes-Rivera, I., Rúas-Araújo, J. y Dapena-González, B. (2017): “Candidatos en Facebook: del texto a la imagen. Análisis de actividad y atención visual", en Revista Dígitos, 1(3), pp. 51-93.

Reyero Simón, L., y Cordero Verdugo, R. R. (2020). Marketing político 3.0: cómo Podemos, Ciudadanos y Vox han cambiado las reglas del juego. Madrid: Tecnos.

Rodrigues, U. (2020): "Political Communication on Social Media Platforms", en Athique, A. y Parthasarathi, V. (Ed). Platform Capitalism in India. Cham: Palgrave Macmillan, pp. 221-238.

Ruano, S. (2009): “Internet y la telefonía móvil nuevos soportes para distribuir contenidos audiovisuales", en Razón y palabra, 14(68). Disponible en Internet: https://www.razonypalabra. 


\section{org.mx/N/n68/varia/ruano.html [Consulta: 6 de Noviembre de 2020]}

Sierra, J. y Lavín, J.M. (coords.) (2019). Redes sociales, tecnologías digitales y narrativas interactivas en la sociedad de la información. Madrid: McGraw-Hill Interamericana España.

Valera-Ordaz, L., Calvo, D. y López-García, G. (2018): “Conversaciones políticas en Facebook. Explorando el papel de la homofilia en la argumentación y la interacción comunicativa", en Revista Latina de Comunicación Social, 73, pp. 55-73. Disponible en Internet: http://www. revistalatinacs.org/073paper/1245/04es.html [Consulta: 14 de Noviembre de 2020]

Van Dijck, J. (2019). La cultura de la conectividad: una historia crítica de las redes sociales. Madrid: Siglo XXI Editores.

Vesnic-Alujevic, L. (2012): "Political participation and web 2.0 in Europe:A case study of Facebook”, en Public relations review, 38(3), pp. 466-470. Disponible en: https://doi.org/10.1016/j. pubrev.2012.01.010 [Consulta: 1 de Noviembre de 2020]

White, D.(1950): “The gatekeeper: A case study in the selection of news”, en Journalism Quarterly, 27, pp. 383-90. Disponible en Internet: https://doi.org/10.1177/107769905002700403[Consulta: 20 de Noviembre de 2020]

Wolf, M. (2005): La investigación de la comunicación de masas. La Habana: Editorial Pablo de la Torriente.

Zannettou, S., Bradlyn, B., De Cristofaro, E., Kwak, H., Sirivianos, M., Stringini, G. y Blackburn, J. (2018): "What is gab: A bastion of free speech or an alt-right echo chamber", en Companion Proceedings of the The Web Conference 2018, pp. 1007-1014. Disponible en Internet: https:// doi.org/10.1145/3184558.3191531 [Consulta: 13 de Noviembre de 2020]

Zhou, Y., Dredze, M., Broniatowski, D. A. y Adler, W. D. (2019): “Elites and foreign actors among the alt-right: The Gab social media platform", en First Monday, 24(9). Disponible en Internet: https://doi.org/10.5210/fm.v24i9.10062 [Consulta: 2 de Noviembre de 2020] 